\title{
Kissing Descartes Good Bye
}

\author{
Harald Walach ${ }^{a}$ David Pincus ${ }^{b}$ \\ anstitute of Transcultural Health Studies, European University Viadrina, Frankfurt (Oder), Germany \\ ${ }^{b}$ Crean School of Health and Life Sciences, Chapman University, Orange, CA, USA
}

Make no mistake: Descartes was a genius and probably one of the most influential writers since Aristotle. His greatest achievement was that he had the - then - brilliant idea that organisms, and humans at that, can be conceptualized as mechanical automatons, machines that function through the conveyance of hydraulic force, just like mechanical clocks. What was extraordinarily daring at Descartes' time has become the mainstream metaphor of the modern scientific age. Organisms have been and are being viewed as machines. The whole analytical power of our modern scientific enterprise in medicine is built on that metaphor. If you have a machine, you can analyze its parts, study their functioning, put it back together, and if something breaks, you can repair it or fit in spares. Emergency medicine, surgery, infection control, and a load of other biomedical achievements testify to the power of this metaphor and to the usefulness of applying it.

However, what many people have started to notice is that this metaphor only works well for analytical purposes and in medicine for acute care problems. It is quite at a loss with most complex medical conditions, functional problems, psychotherapeutic challenges, and chronic diseases. These constitute roughly 70 to $80 \%$ of a patient load in a normal general practitioner clinic, and up to $100 \%$ of the patient load in all psychotherapeutic, counseling, psychosomatic, and probably even complementary practitioners' clinics. Hence, and quite surreptitiously, a lot of patients have sought out these alternatives, because they instinctively see that their problems need a more holistic approach than the mainstream mechanical model affords. This has created a tectonic shift in power and put some strain on the seemingly smooth division line between conventional medicine and alternative practitioners. Patients are deserting conventional treatments and are putting money and effort into complementary ones [1]. Mainstream scientists bark back: 'not scientific, not according to our standards anyway' [2].

Now the point is: what exactly is meant by 'scientific'? If you mean by 'scientific' capable of being modeled according to the mechanistic metaphor, then this is quite correct. Most of the approaches used by complementary and alternative medicine (CAM), and indeed by all therapeutic models that offer a complex package of care - physical therapies, surgery, general practice and family medicine, psychotherapy, psychosomatic treatments, mind-body medicine - cannot be modeled along the lines laid out by the mechanistic paradigm. Not only cannot they be modeled along those lines, they should not. They require a completely different model, one that can handle those complex interactions among the various aspects of treatment, the various aspects of a patient and his or her individual way of looking at the world, of experiencing the illness, and his or her reactions to those experiences including the package of care applied. But how, if not mechanistically, can this be modeled?

Enter 'Complexity Theory', a bastard child of Aristotle and more recently of modern science. Indeed, it was Aristotle who coined the phrase: 'The whole is larger than the sum of its parts', which has become the center piece of general systems theory (GST). Introduced by Ludwig von Bertalanffy [3] and like-minded colleagues like Albert Szent-Gyoergyi [4] in the 1960s, following earlier and similar attempts by Gestalt psychologists like Max Wertheimer and Kurt Lewin, GST was a first major theoretical revolt within the biological sciences against the mainstream of mechanistic thinking. GST became quite popular and successful in biology and the modeling therein. Some great minds like Gregory Bateson exported the thinking of systems theory into psychology [5, 6], epistemolgoy and social theory, where Niklas Luhmann and others made use of it [7]. But medicine did not really take much notice, apart from a few minor exceptions. In came chemists, like Eigen [8] and Prigogine [9]. They discovered that chemical processes can self-organize, and once they do, exhibit strange collective behavior. Ilya Prigogine won the Nobel prize for his discovery that complex systems involved in the exchange of energy, information, or matter can display irreversible second-order transformations. Such chemical dynamics defy mechanistic assumptions, as parts lose their modular nature and cease to function as parts, while global system

\section{KARGER}

Fax +497614520714

Information@Karger.de

www.karger.com
(C) 2012 S. Karger GmbH, Freiburg

$1661-4119 / 11 / 0197-0001 \$ 38.00 / 0$

Accessible online at:

www.karger.com/fok
Prof. Dr. Dr. Harald Walach

Institut für transkulturelle Gesundheitswissenschaften

Europa-Universität Viadrina

Große Scharnstraße 59, 15230 Frankfurt/O., Germany

walach@europa-uni.de 
dynamics appear to violate the second law of thermodynamics, becoming more locally coherent - less entropic - by exporting entropy into surrounding systems. Prigogine modeled these systems using nonlinear differential equations, grounding the conceptual ideas of GST in more formal and specific rules of mathematics. However, if you try to solve such equations, they reach points that are not determined, and after those points the equation has two solutions or even more, describing alternative trajectories the system might take. Just which one it will take cannot be determined, irrespective of the level of detail within the model. Such systems contain degrees of freedom not thought of before. This finding was, conceptually speaking, the end of the fantasy of Descartes' mechanical determinism in the natural sciences. If already simple chemical reaction chains exhibit such behavior, what would happen if, in a complex organism, many such nonlinear and undetermined systems would combine? Simple. Larger systems with more degrees of freedom and less predictability. In the case of the most complex systems, such as human beings, or human societies, you approach infinite degrees of freedom. In other words, it is not possible to predict or engineer these systems in reversible, modular, or mechanistic terms. The abstraction Descartes had introduced fails completely. A human organism is not essentially a machine. It is fundamentally a highly complex system that builds through irreversible and unpredictable processes.

The marriage of systems theory with the theory of complexity and nonlinear modeling has produced a powerful new paradigm [10] that is slowly making its way from the Olympic heights of high-profile scientific theory, modeling and methodology into the netherworld of clinical practice [11, 12]. This is quite understandable. Complexity offers a new way of understanding phenomena that have hitherto been outside the scope of science. Suddenly such phenomena can be treated 'scientifically', albeit with another type, a more modern, more apt and more powerful type of science. The meeting point for marriage, oddly enough, seems to be complementary and holistic approaches to health. For it is here that highly complex interventions, designed beyond notions of simple cause and effect, are conceptualized using signs and symbols that interact within a complex system, producing solutions that are novel, yet inherently unpredictable. These solution outcomes are, ideally, healing [13], yet the path to healing is multifaceted, not traceable to a simple 'causal' ingredient, but rather to the multiple interactions among 'ingredients' at the level of the whole system, including a significant role for self-healing.

These new developments are exciting and at the forefront of scientific theory building. Just how cutting edge it is, and how it can be applied to modeling and research problems in CAM, is the focus of this special issue of Forschende KomPlementärmedizin/Research in Complementary Medicine. The articles collected here are the outcome of various expert meetings and workshops described in the introductory paper by Verhoef et al. This complexity approach provides a powerful new tool. One has to get used to its language and to some new ways of thinking, presented by two introductory chapters by Koithan and colleagues covering theory and by Bell and coworkers discussing research methods. But the effort is worth your while. Pincus demonstrates how complexity can be applied to understand practitioner-patient interactions, to model them and to actually carry out research in this emerging field. Further papers illustrate applications, discuss concrete and practicable tools for measuring holistic and temporal patterns (Howerter et al. and Frantz), and even how insights from gene research can be transferred to research problems within CAM (Abu-Asab et al.). This is a challenging issue, which we hope will stimulate debate. If it does only one thing, we will be completely satisfied: We aim to show that 'scientific' has indeed a much deeper meaning than that which is often used as an armament against new insights. Scientific means 'cutting edge' and the papers collected here show that complex interventions, such as CAM interventions, and according theories are indeed cutting edge, because they can only really be understood, modeled, and tested fruitfully by using complexity theory. And such is the state at the forefront of science. So, kiss Descartes goodbye, at last and finally. Welcome Complexity!

\section{References}

1 Eisenberg DM, Davis RB, Ettner SL, Appel S, Wilkey S, Van Rompay M, Kessler RC: Trends in alternative medicine use in the United States, 1990-1997. J Am Med Assoc 1998;280:1569-1575.

$\checkmark 2$ Colquhoun D: Science degrees without the science. Nature 2007;446:373-374.

3 Bertalanffy Lv: General System Theory. New York, Braziller, 1968.

4 Szent-Gyoergyi A: Drive in living matter to perfect itself. Synthesis 1974:12-24.

5 Bateson G: Steps to an Ecology of Mind. New York, Chandler, 1982.
6 Watzlawick P, Beavin JH, Jackson DD: Menschliche Kommunikation. Formen, Störungen, Paradoxien. Bern, Huber, 1969.

7 Luhmann N: Soziale Systeme. Grundriß einer allgemeinen Theorie. Frankfurt, Suhrkamp, 1984.

8 Eigen M, Schuster P: The Hypercycle. A Principle of Natural Self-Organization. Heidelberg, Springer, 1979.

9 Nicolis G, Prigogine I: Self-Organization in Nonequilibrium Systems. New York, Wiley, 1977.
10 Walleczek J (ed): Self-Organized Biological Dynamics and Nonlinear Control. Toward Understanding Complexity, Chaos and Emergent Function. Cambridge, Cambridge University Press, 2000.

11 Barabasi AL, Gulbahce N, Loscalzo J: Network medicine: a network-based approach to human disease. Nat Rev Genet 2011;12:56-68.

12 del Sol A, Balling R, Hood L, Galas D: Diseases as network perturbations. Curr Opin Biotechnol 2010;21:566-571.

13 Hyland ME: The intelligent body and its discontents. J Health Psychol 2002;7:21-32. 